\title{
Stonefly Larvae Push-ups: A Behavioral Ecology Lab Exercise
}

\section{Brian Swisher}

\author{
Saint Michael's College, Department of Biology, One Winooski Park, Colchester VT 05439 \\ USA
}

(bswisher@smcvt.edu)

\begin{abstract}
The behavioral response of stonefly larvae to the physiological stress of low dissolved oxygen is easy to quantify in the laboratory and lends itself to connections to water quality, animal morphology and physiology, and behavioral traits of animals. Designed for a 2 to $3 \mathrm{hr}$ laboratory for animal behavior, this lab experiment can be conducted with minimal equipment and generates statistically significant results with relatively low number of replicates. The widespread availability of larval stoneflies of the Family Perlidae makes this lab possible wherever there are streams with good to excellent water quality. By using the available literature on the use of aquatic invertebrates to monitor water quality, students can connect a conspicuous and engaging animal behavior to ecological methods used widely around the world.
\end{abstract}

Keywords: stone fly larva, dissolved oxygen levels, aquatic invertebrates, behavioral ecology

\section{Mission, Review Process \& Disclaimer}

The Association for Biology Laboratory Education (ABLE) was founded in 1979 to promote information exchange among university and college educators actively concerned with teaching biology in a laboratory setting. The focus of ABLE is to improve the undergraduate biology laboratory experience by promoting the development and dissemination of interesting, innovative, and reliable laboratory exercises. For more information about ABLE, please visit http://www.ableweb.org/.

Advances in Biology Laboratory Education is the peer-reviewed publication of the conference of the Association for Biology Laboratory Education. Published articles and extended abstracts are evaluated and selected by a committee prior to presentation at the conference, peer-reviewed by participants at the conference, and edited by members of the ABLE Editorial Board. Published abstracts are evaluated and selected by a committee prior to presentation at the conference.

\section{Citing This Article}

Swisher B. 2020. Stonefly larvae push-ups: a behavioral ecology lab exercise. Article 84 In: McMahon K, editor. Advances in biology laboratory education. Volume 41. Publication of the 41st Conference of the Association for Biology Laboratory Education (ABLE). https://doi.org/10.37590/able.v41.abs84

Compilation (C 2020 by the Association for Biology Laboratory Education, ISBN 1-890444-17-0. All rights reserved. No part of this publication may be reproduced, stored in a retrieval system, or transmitted, in any form or by any means, electronic, mechanical, photocopying, recording, or otherwise, without the prior written permission of the copyright owner.

ABLE strongly encourages individuals to use the exercises in this volume in their teaching program. If this exercise is used solely at one's own institution with no intent for profit, it is excluded from the preceding copyright restriction, unless otherwise noted on the copyright notice of the individual chapter in this volume. Proper credit to this publication must be included in your laboratory outline for each use; a sample citation is given above. 